\title{
Predictors of withdrawal from renal replacement therapy among patients with acute kidney injury requiring renal replacement therapy
}

\author{
Katsuhito Ihara ${ }^{1,2} \cdot$ Junichi Ishigami $^{3} \cdot$ Seiji Inoshita $^{1}$
}

Received: 22 September 2018 / Accepted: 31 January 2019 / Published online: 16 February 2019

(c) Japanese Society of Nephrology 2019

\begin{abstract}
Background Although recovery of renal function after an episode of acute kidney injury (AKI) is an important clinical measure of morbidity, predictors of withdrawal from renal replacement therapy (RRT) among AKI patients remain unclear. Methods In this single-center retrospective cohort study, we examined the clinical records of AKI patients requiring RRT who were hospitalized in the ICU or general wards at our hospital from January 2010 to December 2013. A priori-determined covariates of age, sex, cardiovascular disease, chronic kidney disease (CKD), mean arterial pressure (MAP), sepsis, nephrotoxic agents, and hypoalbuminemia were assessed in Cox hazard models to estimate hazard ratio (HR).

Results A total of 334 patients were enrolled (median age, 68 years; interquartile range [IQR], 57-77 years; male, 71.6\%). During follow-up 157 (47.0\%) patients achieved RRT withdrawal. Multivariable Cox regression analysis revealed that CKD, MAP between 95 and $105 \mathrm{mmHg}$ and MAP $\geq 105 \mathrm{mmHg}$, compared with MAP between 65 and $75 \mathrm{mmHg}$, ventilator use and hypoalbuminemia, were significantly associated with RRT withdrawal.

Conclusion Among patients with AKI requiring RRT, CKD, ventilator use, hypoalbuminemia, and high MAP were associated with RRT withdrawal. Furthermore, keeping a higher MAP at RRT initiation can potentially lead to dependence on RRT.
\end{abstract}

Keywords Acute kidney injury (AKI) · Renal replacement therapy (RRT) · AKI requiring RRT · Predictors ·

Discontinuation $\cdot$ Withdrawal

\section{Introduction}

The mortality of patients with severe acute kidney injury (AKI) is $60.3 \%$, despite advances in renal replacement therapies (RRT) and critical care medicine [1]. According to the Kidney Disease: Improving Global Outcome (KDIGO) guideline, AKI requiring RRT is equivalent to AKI stage 3 (severe AKI) [2], and mortality associated with severe

Katsuhito Ihara

ctngt512@yahoo.co.jp

1 Department of Internal Medicine, Tokyo Metropolitan Bokutoh Hospital, 4-23-15 Kotobashi, Sumida-ku, Tokyo 130-8575, Japan

2 Department of Epidemiology, Harvard T. H. Chan School of Public Health, 677 Huntington Avenue, Boston, MA 02115, USA

3 Department of Epidemiology, Johns Hopkins Bloomberg School of Public Health, 615 N. Wolfe Street, Baltimore 21205, MD, USA
AKI is one of the highest observed outcomes. Studies from administrative databases provide evidence that the incidence of AKI and AKI requiring RRT have significantly increased [3, 4], and crude case-fatality has increased likely due to the increasing age and comorbidity burden of patients [4]. Moreover, even if patients could survive severe AKI, 24.6\% of patients still receive RRT on day 60 from AKI onset [5] and the independent rate from RRT decreases to $25.8 \%$ at 1 year [6].

Apart from mortality, renal outcomes after AKI are crucial. Surveys show that the growth in incident end-stage renal disease (ESRD) outpaced the growth in prevalent chronic kidney disease (CKD), demonstrating that the increasing number of ESRD is not simply due to an increasing number of CKD [7]. An episode of AKI can deteriorate renal function over time after hospital discharge, and especially AKI requiring RRT significantly increases the risk of chronic dialysis [8], which negatively impacts quality of life and poses a huge financial burden. 
Despite the devastating consequence of AKI, factors associated with withdrawal from RRT among AKI patients have remained unclear. Previous studies primarily focused on risk factors associated with development of AKI, whereas predictors of RRT withdrawal among patients with AKI requiring RRT are largely unknown. To make our study closer to clinical practice and identify modifiable determinants, we considered the target range of MAP at RRT initiation, which was different from the previous studies [9-11]. Therefore, we conducted a study to determine predictors of withdrawal from RRT among patients with AKI requiring RRT.

\section{Materials and methods}

\section{Study participants and study base}

We retrospectively examined the clinical records of AKI patients requiring RRT in the Tokyo Metropolitan Bokutoh Hospital, an urban teaching hospital and a tertiary care center, from January 2010 to December 2013. To assemble our study population from medical records, we took the following steps: (1) we created a roster of information on every RRT performed in either ICU or dialysis room during this period and identified each individual; (2) for patients with multiple admissions during this period, only the first hospitalization was analyzed; (3) to confirm whether or not the patients on the list previously experienced RRT before this study period, we looked at their medical records one by one; (4) we excluded patients on maintenance RRT including hemodialysis, hemofiltration or peritoneal dialysis; (5) we evaluated whether each RRT was performed for AKI among the patients and included the patients with AKI requiring RRT, based on the definition of AKI in the KDIGO criteria [2]. After establishing the study base, for each patient, demographics, clinical information, medical record reviews, laboratory measures, and detailed information about RRT were ascertained from a common comprehensive electronic medical record.

\section{Outcome}

Primary outcome was withdrawal from RRT at the end of follow-up, defined as being free from RRT and never resuming after stopping therapy during hospitalization. This outcome was chosen because it is clinically meaningful and has been associated with morbidity and health care costs. In our hospital, each physician decided to discontinue of RRT when intrinsic renal function had adequately recovered [2], without pre-specified criteria. Follow-up was continued until they died, were discharged alive or were lost to follow-up due to transfer to other hospitals. Evaluating the descriptions in the medical records in detail enabled us to accurately verify each patient's condition. For patients under severe and end-of-the life conditions, we distinguished them from those who were able to discontinue RRT because of renal recovery.

\section{Clinical evaluation}

To determine covariates, we systematically performed a literature review, focusing on the association between AKI requiring RRT and outcome. This was because we hypothesized determinants and confounders of mortality, among patients with AKI requiring RRT, might share the causal diagram with RRT withdrawal from the perspective of etiological model. In addition, among the covariates from the previous studies [12-21], we considered the retrospective feasibility of collecting their information, and finally determined covariates.

The demographic information was extracted from the electrical medical chart review on admission. Regarding physiological data, we retrieved information on blood pressure measured at the beginning of RRT, and if not available, we used the measurements at least $10 \mathrm{~min}$ before RRT initiation. Mean arterial pressure (MAP) was calculated by (systolic blood pressure $+2 \times$ diastolic blood pressure) $/ 3$. Chronic medical conditions included cardiovascular disease (CVD), cerebrovascular accident (CVA), CKD, diabetes mellitus (DM), hypertension, arteriosclerosis obliterans (ASO), chronic obstructive pulmonary disease (COPD), liver disease, and malignancies. The information on comorbidities was referred to medical records and any referral letters from other facilities. If the patient had been admitted before, we attempted to extract and verify the information on comorbidities. Between admission and the initiation of RRT during the corresponding hospitalizations, if the patient was eligible, we retrieved information on the following variables: administration of vasopressors, mechanical ventilation, surgery, sepsis, infection, nephrotoxic agents, and diuretics. The information on administrations of angiotensinconverting enzyme (ACE) inhibitor, angiotensin II receptor blockers (ARB) or $\beta$-blockers was collected under the same approach. CVD included a history of myocardial infarction, angina pectoris, and heart failure. CVA contained a history of brain hemorrhage, brain infarction, subarachnoid hemorrhage, and transient ischemic attack. CKD was defined by the description of medical history on the medical charts or detected if the laboratory data before admission were available. Surgery was defined as experience of any surgeries before RRT initiation during the hospitalization. Sepsis, the most common cause of AKI in critical illness and septic $\mathrm{AKI}$ is associated with poor prognosis [22,23], was defined according to the consensus guideline before RRT initiation [24]. We collected information about the use of diuretics $[25,26]$ for proxy of fluid overload [27]. Nephrotoxic agents 
included non-steroidal anti-inflammatory drugs (NSAIDs), antibiotics, and contrast medium. The laboratory data were obtained from the latest information on samples prior to RRT initiation at the same days. Anemia was defined as hemoglobin level below $10.0 \mathrm{~g} / \mathrm{dL}$ based on the reference range of starting erythropoiesis-stimulating agent according to the KDIGO guideline for anemia [28]. Hypoalbuminemia was defined as level of serum albumin below $2.5 \mathrm{~g} / \mathrm{dL}$ based on previous studies $[29,30]$. Hyponatremia was defined as level of sodium below $135 \mathrm{mEq} / \mathrm{L}$ based on reference range at our hospital. To reduce the misclassification and measurement error when retrieving the medical information, we reviewed data by three independent board-certified nephrologists.

\section{Statistical analysis}

To evaluate normal distribution, we conducted the Shapiro-Wilk test at the 0.05 level of significance. Based on the result of the test, continuous variables are expressed as mean \pm standard deviation (SD) for variables whose underlying distributions were regarded as normal or median (interquartile range [IQR], 25th and 75th percentiles) values for not as normal. Categorical variables are expressed in frequency and percentage. To reflect clinical practice based on the recommendation of AKI guideline [2], MAP was categorized into $<65 \mathrm{mmHg}, \geq 65$ and $<75 \mathrm{mmHg}$, $\geq 75$ and $<85 \mathrm{mmHg}, \geq 85$ and $<95 \mathrm{mmHg}, \geq 95 \mathrm{mmHg}$ and $<105 \mathrm{mmHg}$, and $\geq 105 \mathrm{mmHg}$ for reference on MAP between 65 and $75 \mathrm{mmHg}$. Difference in distributions of each continuous variable was analyzed using Student's $t$ test for variables underlying normal distribution and Wilcoxon rank-sum test for non-normal. Categorical variables were compared using the Chi-square test or Fisher's exact test as appropriate. To deal with missing values in our analyses, we conducted complete case analyses. To account for varying length of follow-up, survival analysis methods should be used. Cox regression analyses were used to estimate hazard ratios (HRs) and 95\% confidence intervals (95\% CIs). First, we performed univariate Cox regression analysis for each of the covariates. Next, we accounted for several known risk factors of AKI in our model, based on prior studies (age [12, $14,18]$ and sex [21], CVD [14, 15], CKD, MAP [31], sepsis [22, 23], nephrotoxic agents, and hypoalbuminemia [29, 30]). Moreover, we included anemia as a significant predictor resulting from the univariate analysis. Finally, among the nonsignificant predictors in the univarite analysis, ventilator use was subsequently added to the model because it showed a significant association in the multivariable Cox regression model. Subgroup analyses were performed because different mechanisms according to different demographics, physiologic conditions, and comorbidities have been suggested to explain the effect of baseline MAP on RRT withdrawal; age, sex, DM, hypertension, CKD, sepsis, nephrotoxic agents, hypoalbuminemia, and vasopressor use. We estimated the effect of MAP on RRT withdrawal by change in quartiles for simplicity. To examine the effect of multiplicative interaction, we performed log-likelihood ratio tests comparing models with and without the interaction term. We also performed subgroup analyses to explore whether RRT withdrawal was associated with underlying severity of the conditions among patients, which is simply implied in the admission status, either ICU or general ward. In sensitivity analysis, we restricted analyses to survivors to account for the competing risk of death. All analyses were performed using the Statistical Package for Social Science (SPSS ${ }^{\circledR}$ ) for Windows, version 23.0 (IBM, Chicago, IL, USA) or SAS for windows, version 9.4 (SAS Institute, Cary, NC). Twosided $p$ values of less than 0.05 were considered statistically significant.

\section{Results}

\section{Patient characteristics}

A total of 334 patients were included in the analysis. Baseline characteristics are shown in Table 1. According to the descriptions of medical records, we were able to categorize the indications for RRT into oliguria, azotemia with increase of BUN and/or serum Cr, fluid overload, acidosis, and hyperkalemia, although physicians at our hospital did not follow any pre-specified criteria of each category (i.e., oliguria on medical records did not necessarily match the criteria of urinary volume of less than $0.5 \mathrm{~mL} / \mathrm{kg}$ for $6 \mathrm{~h}$ in KDIGO guideline [2]). Based on a definition of community-acquired AKI $[32,33]$, the number of patients with AKI requiring RRT within $48 \mathrm{~h}$ after admissions was 230 (68.9\%). Missing rates of information on covariates were $0.9 \%$ of CVD, $0.6 \%$ of CVA, CKD, DM, hypertension, ASD, hepatic failure, malignancy, $0.3 \%$ of COPD, $4.5 \%$ of ACE inhibitor or ARB use, and $4.2 \%$ of $\beta$-blocker use. The median age was 68 years (IQR $57-77$ years), and 71.6\% were men. Regarding medical history, 36.3\% had CVD, 39.8\% had CKD, and $36.7 \%$ had DM. The median MAP was $78.7 \mathrm{mmHg}$ (IQR $65.3-96.3 \mathrm{mmHg}$ ). Vasopressors were used in $167(50.0 \%)$ patients. Nearly half of the patients were diagnosed with sepsis, 156 (46.7\%), at initiation of RRT. Nephrotoxic agents before RRT initiation were used $57.2 \%$ of patients. Patients admitted to ICU were the majority of our study population (77.8\%). As expected, ICU patients were significantly under severer condition (e.g., lower median MAP, more use of ventilator, sepsis, etc.) compared with those who were in general ward, while those in general ward had more comorbidities such as CKD, hypertension, and malignancy. 
Table 1 Baseline characteristics of the study population

\begin{tabular}{|c|c|c|c|c|}
\hline & Total $N=334$ & ICU $N=260(77.8 \%)$ & General ward $N=74(22.2 \%)$ & $P$ value \\
\hline Age & 68 [57-77] & 68 [57-77] & $69[60-77]$ & 0.369 \\
\hline Male & 239 (71.6) & $185(71.2)$ & $54(73.0)$ & 0.760 \\
\hline RRT indication & & & & 0.098 \\
\hline Oliguria & $188(56.3)$ & $152(58.5)$ & $36(48.7)$ & \\
\hline Azotemia & $83(24.9)$ & $61(23.5)$ & $22(29.7)$ & \\
\hline Fluid overload & $51(15.3)$ & $35(13.5)$ & $16(21.6)$ & \\
\hline Acidosis & $6(1.8)$ & $6(2.3)$ & $0(0.0)$ & \\
\hline Hyperkalemia & $6(1.8)$ & $6(2.3)$ & $0(0.0)$ & \\
\hline MAP (mmHg) & $78.7[65.3-96.3]$ & $75.8[63.0-89.8]$ & $92.1[81.0-107.3]$ & $<0.0001$ \\
\hline MAP $<65$ & $79(23.7)$ & $73(28.1)$ & $6(8.1)$ & $<0.0001$ \\
\hline $65 \leq \mathrm{MAP}<75$ & $58(17.4)$ & $51(19.6)$ & $7(9.5)$ & \\
\hline $75 \leq \mathrm{MAP}<85$ & $67(20.1)$ & $55(21.2)$ & $12(16.2)$ & \\
\hline $85 \leq \mathrm{MAP}<95$ & $37(11.1)$ & $23(8.9)$ & $14(18.9)$ & \\
\hline $95 \leq \mathrm{MAP}<105$ & $34(10.2)$ & $20(7.7)$ & $14(18.9)$ & \\
\hline $105 \leq \mathrm{MAP}$ & $59(17.7)$ & $38(14.6)$ & $21(28.4)$ & \\
\hline Vasopressor administration & $167(50.0)$ & $157(60.4)$ & $10(13.5)$ & $<0.0001$ \\
\hline Ventilator use & $196(58.7)$ & $185(71.2)$ & $11(14.9)$ & $<0.0001$ \\
\hline Surgery & $71(21.3)$ & $68(26.2)$ & $3(4.1)$ & $<0.0001$ \\
\hline Sepsis & $156(46.7)$ & $133(51.2)$ & $23(31.2)$ & 0.002 \\
\hline Nephrotoxic agent use & $191(57.2)$ & $175(67.3)$ & $16(21.6)$ & $<0.0001$ \\
\hline Diuretics & $133(39.8)$ & $95(36.5)$ & $38(51.4)$ & 0.022 \\
\hline Continuous RRT & $146(43.7)$ & $146(56.2)$ & $0(0.0)$ & $<0.0001$ \\
\hline \multicolumn{5}{|l|}{ Comorbidities } \\
\hline CVD & $120(36.3)$ & $102(39.7)$ & $18(24.3)$ & 0.015 \\
\hline CVA & $52(15.7)$ & $39(15.1)$ & $13(17.6)$ & 0.609 \\
\hline CKD & $130(39.2)$ & 79 (30.6) & $51(68.9)$ & $<0.0001$ \\
\hline $\mathrm{DM}$ & $123(37.0)$ & $91(35.3)$ & $32(43.2)$ & 0.211 \\
\hline Hypertension & $208(62.7)$ & $146(56.6)$ & $62(83.8)$ & $<0.0001$ \\
\hline ASO & $21(6.3)$ & $19(7.4)$ & $2(2.7)$ & 0.146 \\
\hline COPD & $19(5.7)$ & $15(5.8)$ & $4(5.4)$ & 0.900 \\
\hline Hepatic failure & $69(20.8)$ & $56(21.7)$ & $13(17.6)$ & 0.439 \\
\hline Malignancy & $59(17.8)$ & $38(14.7)$ & $21(28.4)$ & 0.007 \\
\hline ACEi/ARB use & $113(35.4)$ & $74(30.2)$ & $39(52.7)$ & 0.0004 \\
\hline Beta blocker use & $42(13.1)$ & $34(13.8)$ & $8(10.8)$ & 0.501 \\
\hline \multicolumn{5}{|l|}{ Laboratory } \\
\hline $\mathrm{WBC}\left(\times 10^{3} / \mathrm{mm}^{3}\right)$ & $10.6[7.2-15.4]$ & $11.4[7.6-16.4]$ & $8.8[5.7-12.2]$ & 0.001 \\
\hline $\mathrm{Hb}(\mathrm{g} / \mathrm{dL})$ & 9.7 [8.2-12.2] & $10.2[8.6-12.7]$ & 8.6 [7.3-10.3] & $<0.0001$ \\
\hline Ht $(\%)$ & $29.1[24.7-36.5]$ & $30.2[25.8-37.4]$ & $25.6[21.8-30.6]$ & $<0.0001$ \\
\hline Anemia & $175(52.4)$ & $124(47.7)$ & $51(68.9)$ & $<0.0001$ \\
\hline Plt $\left(\times 10^{4} / \mathrm{mm}^{3}\right)$ & $13.3[7.3-20.6]$ & $12.2[6.1-19.2]$ & $16.3[12.4-24.2]$ & 0.0002 \\
\hline $\mathrm{TP}(\mathrm{g} / \mathrm{dL})$ & $5.6[4.8-6.3]$ & $5.6[4.7-6.3]$ & $5.5[5.0-6.3]$ & 0.704 \\
\hline Alb (g/dL) & $2.6 \pm 0.7$ & $2.7 \pm 0.8$ & $2.5 \pm 0.6$ & 0.017 \\
\hline Hypoalbuminemia & $141(42.2)$ & $106(40.8)$ & $35(47.3)$ & 0.316 \\
\hline BUN (mg/dL) & $68.0[41.0-106.0]$ & $59.0[33.5-89.0]$ & $105.5[78.0-125.0]$ & $<0.0001$ \\
\hline $\mathrm{Cr}(\mathrm{mg} / \mathrm{dL})$ & $4.3[2.5-7.1]$ & $3.7[2.1-5.5]$ & $7.9[6.2-10.4]$ & $<0.0001$ \\
\hline $\mathrm{Na}(\mathrm{mEq} / \mathrm{L})$ & $136.5 \pm 7.5$ & $136.7 \pm 7.8$ & $135.6 \pm 6.0$ & 0.246 \\
\hline Hyponatremia & $130(38.9)$ & 97 (37.3) & $33(44.6)$ & 0.257 \\
\hline $\mathrm{K}(\mathrm{mEq} / \mathrm{L})$ & $4.9[4.1-5.8]$ & $5.0[4.2-6.0]$ & $4.7[4.0-5.7]$ & 0.047 \\
\hline $\mathrm{Cl}(\mathrm{mEq} / \mathrm{L})$ & 103 [98-107] & 103 [98-107] & 103 [98-107] & 0.943 \\
\hline T-Bil (mg/dL) & $0.7[0.4-1.5]$ & 0.9 [0.4-1.9] & $0.4[0.3-0.6]$ & $<0.0001$ \\
\hline $\mathrm{CRP}(\mathrm{mg} / \mathrm{dL})$ & $7.6[1.6-18.2]$ & 8.7 [2.3-19.3] & $4.3[0.9-13.5]$ & 0.010 \\
\hline
\end{tabular}

Values are given as median [interquartile range], $n(\%)$ and mean $\pm \mathrm{SD}$

$M A P$ mean arterial pressure, $R R T$ renal replacement therapy, $C V D$ cardiovascular disease, $C V A$ cerebrovascular accidents, $C K D$ chronic kid- 
Table 1 (continued)

ney disease, $D M$ diabetes mellitus, $A S O$ arteriosclerosis obliterans, $C O P D$ chronic obstructive pulmonary disease, $A C E i$ angiotensin-converting enzyme inhibitors, $A R B$ angiotensin II receptor blocker, $W B C$ white blood cell, $H b$ hemoglobin, $H t$ hematocrit, anemia defined as $\mathrm{Hb}<10.0 \mathrm{~g} /$ $\mathrm{dL}, P l t$ platelet, $T P$ total protein, Alb albumin, hypoalbuminemia defined as Alb $<2.5 \mathrm{~g} / \mathrm{dL}, B U N$ blood urea nitrogen, $C r$ serum creatinine, $N a$ sodium, hyponatremia defined as $\mathrm{Na}<135 \mathrm{mEq} / \mathrm{L}, K$ potassium, $C l$ chloride, $T$-Bil total bilirubin, $C R P$ C-reactive protein

\section{Association between covariates and RRT withdrawal}

Table 2 shows the characteristics of the study population by status of RRT withdrawal. Median follow-up period was 6 days (IQR 2-23 days) and, of the overall population, 47.0\% patients withdrew from RRT. In-hospital mortality between patients who were able to withdraw from RRT and those who were not were $15.9 \%$ and $70.1 \%$, respectively. There was no significant difference in the history of CVD, CKD, $\mathrm{DM}$, hypertension, and MAP at RRT initiation between the two groups, whereas use of ventilator and sepsis on RRT initiation were significantly different. Notably, the mortality in patients who did not withdraw from RRT was significantly higher than that in patients who withdrew. Apparently, the patients who were not able to withdraw from RRT seemed to have more severe conditions.

When predictors of RRT withdrawal were assessed in univariate Cox models (Table 3), significant factors were CKD (HR 0.58, 95\% CI 0.42-0.81, $P=0.001$ ), nephrotoxic agents (HR 1.38, 95\% CI 1.00-1.90, $P=0.048$ ), and anemia (HR $0.60,95 \%$ CI $0.44-0.83, P=0.002$ ).

Table 4 shows the results of multivariable Cox analysis. Model 1 adjusted for age and sex. Model 2 adjusted for predefined covariates (i.e., age and sex, MAP at RRT initiation, history of CVD and CKD, sepsis and use of nephrotoxic agents), anemia, and hypoalbuminemia. Finally, model 3 further adjusted for ventilator use, in addition to the covariates for model 2. In the final model (model 3), CKD (HR $0.63,95 \%$ CI $0.41-0.96, P=0.030$ ), MAP between 95 and $105 \mathrm{mmHg}$ (HR $0.42,95 \%$ CI $0.21-0.85, P=0.015)$ and $\geq 105 \mathrm{mmHg}$ (HR $0.55,95 \%$ CI $0.31-0.96, P=0.036$ ), compared with MAP between 65 and $75 \mathrm{mmHg}$ on the RRT initiation, hypoalbuminemia (HR 0.70, HR 0.49-0.99, $P=0.042$ ), and ventilator use before RRT initiation (HR $0.65,95 \%$ CI $0.44-0.97, P=0.035$ ) remained significant.

Finally, findings from subgroup analyses of MAP at RRT initiation were similar to those of the main analyses (Fig. 1). Both CKD $(P$ for interaction $=0.006)$ and nephrotoxic agents ( $P$ for interaction $=0.001)$ revealed statistical evidence of multiplicative interactions with MAP. Under existence of CKD or nephrotoxic agents, the point estimates of MAP were different between the two groups within categories. Investigating the effect of hemodynamic instability on outcome, we did not confirm a significant difference in MAP between vasopressor users and non-users ( $P$ for interaction $=0.094)$. Moreover, although the ICU patients tended to suffer from lower MAP and administered more vasopressor compared to those who were in general ward (Table 1), the effect estimates of MAP on RRT withdrawal in ICU were similar to those of entire cohort (Table 5). Sepsis in ICU patients revealed significant effect on RRT withdrawal, while CKD did in general ward patients. Each MAP category in general ward did not show any significant effects. However, due to the small number of events among patients in general ward compared with that of determinants in the model, we should pay attention to interpreting the results. Indeed, the effects of MAP from patients between ICU and general ward were similar and there was no interaction between MAP and admitted ward (Fig. 1). Findings from sensitivity analysis accounting for the competing risk of death were also similar to main analyses (Table 6).

\section{Discussion}

In this retrospective cohort study of AKI patients requiring RRT, we found that CKD, ventilator use, hypoalbuminemia, and MAP at RRT initiation were significantly associated with RRT withdrawal after accounting for potential confounders. Particularly, we observed that MAP $\geq 95 \mathrm{mmHg}$ was rather associated with a lower chance of RRT withdrawal, which may indicate a potential targetable intervention to improve the outcome of AKI requiring RRT. Our novelty of findings is shedding light on the insight on target range of MAP at RRT initiation.

We found that CKD was associated with lower chance of RRT withdrawal. Our results were consistent with the previous studies showing the worse outcome following AKI among patients with CKD. One study reports that among patients with AKI treated with dialysis, the incidence of ESRD after 90 days from AKI is 3\% among patients with previous normal renal function, whereas that of $16 \%$ among patients with CKD [34]. Similarly, one RCT suggests that pre-existing CKD is an independent predictor of renal recovery [35]; furthermore, another study shows patients with both AKI and pre-existing or concurrent CKD showed a multiplicative effect on risk for the development of ESRD [36].

The other negatively significant factors of RRT withdrawal were ventilator use and hypoalbuminemia. Although our findings confirmed the previous literature reporting of a higher mortality among AKI patients on ventilator [14, 15] requiring RRT, the underlying mechanisms are not fully understood. Indeed, it is possible that ventilator use could 
Table 2 Comparison between patients with and without withdrawal of RRT

\begin{tabular}{|c|c|c|c|}
\hline & Withdrawal $N=157(47.0 \%)$ & $\begin{array}{l}\text { Non-withdrawal } N=177 \\
(53.0 \%)\end{array}$ & $P$ value \\
\hline Age & $67[55-77]$ & $69[58-77]$ & 0.240 \\
\hline Male & $105(66.9)$ & $134(75.7)$ & 0.074 \\
\hline MAP (mmHg) & $79.0[68.2-96.0]$ & $77.0[62.8-97.7]$ & 0.192 \\
\hline $\mathrm{MAP}<65$ & $28(17.8)$ & $51(28.8)$ & 0.095 \\
\hline $65 \leq \mathrm{MAP}<75$ & $28(17.8)$ & $30(16.9)$ & \\
\hline $75 \leq \mathrm{MAP}<85$ & $40(25.5)$ & $27(15.3)$ & \\
\hline $85 \leq \mathrm{MAP}<95$ & $19(12.1)$ & $18(10.2)$ & \\
\hline $95 \leq \mathrm{MAP}<105$ & $14(8.9)$ & $20(11.3)$ & \\
\hline $105 \leq \mathrm{MAP}$ & $28(17.8)$ & $31(17.5)$ & \\
\hline Vasopressor administration & $70(44.6)$ & $97(54.8)$ & 0.062 \\
\hline Ventilator use & $80(51.0)$ & $116(65.5)$ & 0.007 \\
\hline Surgery & $34(21.7)$ & $37(20.9)$ & 0.867 \\
\hline Sepsis & $61(38.9)$ & $95(53.7)$ & 0.007 \\
\hline Nephrotoxic agent use & $92(58.6)$ & $99(55.9)$ & 0.623 \\
\hline Diuretics & $67(42.7)$ & $66(37.3)$ & 0.315 \\
\hline Continuous RRT & $61(38.9)$ & $85(48.0)$ & 0.092 \\
\hline \multicolumn{4}{|l|}{ Comorbidities } \\
\hline CVD & $54(34.6)$ & $66(37.7)$ & 0.558 \\
\hline CVA & $21(13.4)$ & $31(17.7)$ & 0.278 \\
\hline CKD & $56(35.7)$ & $74(42.3)$ & 0.217 \\
\hline DM & $51(32.5)$ & $72(41.1)$ & 0.103 \\
\hline Hypertension & $97(61.8)$ & $111(63.4)$ & 0.757 \\
\hline ASO & $12(7.6)$ & $9(5.1)$ & 0.350 \\
\hline COPD & $4(2.5)$ & $15(8.5)$ & 0.019 \\
\hline Hepatic failure & $32(20.4)$ & $37(21.1)$ & 0.865 \\
\hline Malignancy & $21(13.4)$ & $38(21.7)$ & 0.047 \\
\hline ACEi/ARB use & $50(32.5)$ & $63(38.2)$ & 0.286 \\
\hline Beta blocker use & $20(12.9)$ & $22(13.3)$ & 0.909 \\
\hline \multicolumn{4}{|l|}{ Laboratory } \\
\hline $\mathrm{WBC}\left(\times 10^{3} / \mathrm{mm}^{3}\right)$ & $11.7[7.9-17.1]$ & $10.0[6.6-14.2]$ & 0.003 \\
\hline $\mathrm{Hb}(\mathrm{g} / \mathrm{dL})$ & $10.1[8.6-12.5]$ & 9.3 [7.9-11.7] & 0.005 \\
\hline Ht (\%) & $30.0[26.2-37.3]$ & $27.9[23.3-35.6]$ & 0.006 \\
\hline Anemia & $75(42.9)$ & $100(57.1)$ & 0.111 \\
\hline Plt $\left(\times 10^{4} / \mathrm{mm}^{3}\right)$ & 13.6 [8.9-20.9] & $13.0[6.1-20.2]$ & 0.150 \\
\hline $\mathrm{TP}(\mathrm{g} / \mathrm{dL})$ & $5.7[5.0-6.5]$ & $5.5[4.6-6.1]$ & 0.039 \\
\hline $\operatorname{Alb}(\mathrm{g} / \mathrm{dL})$ & $2.7 \pm 0.8$ & $2.6 \pm 0.7$ & 0.890 \\
\hline Hypoalbuminemia & $61(43.3)$ & $80(56.7)$ & 0.241 \\
\hline BUN (mg/dL) & $67.0[40.0-103.5]$ & 69.0 [42.0-108.5] & 0.527 \\
\hline $\mathrm{Cr}(\mathrm{mg} / \mathrm{dL})$ & $4.2[2.6-6.6]$ & $4.4[2.3-7.6]$ & 0.236 \\
\hline $\mathrm{Na}(\mathrm{mEq} / \mathrm{L})$ & $135.3 \pm 7.1$ & $137.6 \pm 7.7$ & 0.050 \\
\hline Hyponatremia & $68(43.3)$ & $62(35.0)$ & 0.121 \\
\hline $\mathrm{K}(\mathrm{mEq} / \mathrm{L})$ & $4.9[4.1-5.8]$ & $4.9[4.1-5.9]$ & 0.805 \\
\hline $\mathrm{Cl}(\mathrm{mEq} / \mathrm{L})$ & $103[97-107]$ & $103[98-108]$ & 0.224 \\
\hline T-Bil (mg/dL) & $0.7[0.4-1.3]$ & $0.6[0.3-1.9]$ & 0.390 \\
\hline CRP (mg/dL) & $8.8[1.7-20.1]$ & $7.0[1.4-17.1]$ & 0.464 \\
\hline \multicolumn{4}{|l|}{ Outcome } \\
\hline In-hospital mortality & $25(15.9)$ & $124(70.1)$ & $<0.0001$ \\
\hline Days of RRT withdrawal & 4 [2-9] & $11[2-36]$ & $<0.0001$ \\
\hline
\end{tabular}

Values are given as median [interquartile range], $n(\%)$ and mean $\pm \mathrm{SD}$

$R R T$ renal replacement therapy, MAP mean arterial pressure, $C V D$ cardiovascular disease, CVA cerebrovascular accidents, $C K D$ chronic kidney disease, $D M$ diabetes mellitus, $A S O$ arteriosclerosis obliterans, $C O P D$ chronic obstructive pulmonary disease, $A C E i$ angiotensin-converting enzyme inhibitors, ARB angiotensin II receptor blocker, WBC white blood cell, $H b$ hemoglobin, $H t$ hematocrit, anemia defined as $\mathrm{Hb}<10.0 \mathrm{~g} /$ $\mathrm{dL}$, Plt platelet, $T P$ total protein, Alb albumin, hypoalbuminemia defined as $\mathrm{Alb}<2.5 \mathrm{~g} / \mathrm{dL}, B U N$ blood 
Table 2 (continued)

urea nitrogen, $\mathrm{Cr}$ serum creatinine, $\mathrm{Na}$ sodium, hyponatremia defined as $\mathrm{Na}<135 \mathrm{mEq} / \mathrm{L}, \mathrm{K}$ potassium, $\mathrm{Cl}$ chloride, $T$-Bil total bilirubin, $C R P$ C-reactive protein

Table 3 Univariate analyses for RRT withdrawal in patients with AKI requiring RRT

\begin{tabular}{|c|c|c|c|}
\hline Covariates & Crude HR & $95 \% \mathrm{CI}$ & $P$ value \\
\hline Age & 1.00 & $0.99-1.01$ & 0.482 \\
\hline Male (vs. Female) & 0.82 & $0.59-1.15$ & 0.254 \\
\hline MAP (mmHg) & & & 0.179 \\
\hline MAP $<65$ & 0.98 & $0.58-1.66$ & 0.933 \\
\hline $65 \leq \mathrm{MAP}<75$ & 1.00 & Reference & \\
\hline $75 \leq \mathrm{MAP}<85$ & 1.17 & $0.72-1.90$ & 0.527 \\
\hline $85 \leq \mathrm{MAP}<95$ & 0.85 & $0.47-1.52$ & 0.582 \\
\hline $95 \leq \mathrm{MAP}<105$ & 0.60 & $0.31-1.14$ & 0.116 \\
\hline $105 \leq \mathrm{MAP}$ & 0.66 & $0.39-1.11$ & 0.117 \\
\hline Ventilator use & 0.86 & $0.63-1.18$ & 0.342 \\
\hline CVD & 0.81 & $0.63-1.21$ & 0.413 \\
\hline CKD & 0.58 & $0.42-0.81$ & 0.001 \\
\hline $\mathrm{DM}$ & 0.77 & $0.55-1.07$ & 0.119 \\
\hline ASO & 1.21 & $0.67-2.18$ & 0.532 \\
\hline Surgery & 1.06 & $0.72-1.54$ & 0.781 \\
\hline COPD & 0.38 & $0.14-1.02$ & 0.055 \\
\hline Hepatic failure & 1.13 & $0.77-1.67$ & 0.538 \\
\hline Malignancy & 0.70 & $0.44-1.11$ & 0.127 \\
\hline Sepsis & 0.87 & $0.63-1.20$ & 0.399 \\
\hline Nephrotox & 1.38 & $1.00-1.90$ & 0.048 \\
\hline Diuretics & 0.90 & $0.65-1.23$ & 0.505 \\
\hline Anemia & 0.60 & $0.44-0.83$ & 0.002 \\
\hline Hypoalbuminemia & 0.76 & $0.55-1.05$ & 0.101 \\
\hline Hyponatremia & 1.20 & $0.87-1.65$ & 0.259 \\
\hline
\end{tabular}

$R R T$ renal replacement therapy, $A K I$ acute kidney injury, $H R$ hazard ratio, $C I$ confidence interval, $M A P$ mean arterial pressure, $C V D$ cardiovascular disease, CVA cerebrovascular accidents, $C K D$ chronic kidney disease, $D M$ diabetes mellitus, $A S O$ arteriosclerosis obliterans, $C O P D$ chronic obstructive pulmonary disease, anemia defined as $\mathrm{Hb}<10.0 \mathrm{~g} / \mathrm{dL}$, hypoalbuminemia defined as $\mathrm{Alb}<2.5 \mathrm{~g} / \mathrm{dL}$, hyponatremia defined as $\mathrm{Na}<135 \mathrm{mEq} / \mathrm{L}$

be surrogate of sicker underlying disease conditions, rather than the predictor by itself. As illustrated, future studies are needed to better understand the roles of ventilator use on AKI outcomes using sufficient information about potential mediator and confounders. On the other hand, several studies suggested serum albumin itself could protect the kidneys from toxic agents and maintain the renal perfusion [29, 30]. Therefore, hypoalbuminemia is more likely to be related to the extent of the renal dysfunction, leading to failure in RRT withdrawal.

A novel finding of our study is a low chance of RRT withdrawal among patients with high MAP at the time of RRT initiation. In practice, we usually try to keep the $\mathrm{MAP} \geq 65 \mathrm{mmHg}$ based on the AKI guideline [2]. However, little is known about the optimal MAP target. In our study, patients with MAP of 95-105 and $\geq 105 \mathrm{mmHg}$ had a lower chance of RRT withdrawal, which suggests higher MAP such as $95 \mathrm{mmHg}$ is not the optimal target compared to MAP 65-75 $\mathrm{mmHg}$ regardless of vasopressor administration. Since we can regard MAP as renal perfusion, we assume that the higher MAP prevents kidney from further damage. However, if we assume the renal autoregulation after AKI is deteriorated, higher blood pressure could easily induce more damage to glomerulus such as hypertension-induced renal damage [37], which is compatible with our observed results. There are a few reports concerning blood pressure related to mortality among AKI requiring RRT [17, 31], and instead of renal prognosis, some reports disclose better prognosis with higher MAP among AKI. Among patients with postgastrointestinal surgery, the MAP comparing $80-95 \mathrm{mmHg}$ with $65-79 \mathrm{mmHg}$ is reported to have less incidence of AKI [38], and among patients with AKI requiring RRT after cardiac surgery, the lower MAP is associated with poor mortality [39]. As our results showed, the higher MAP would not be optimal rather than sole target of MAP $\geq 65 \mathrm{mmHg}$. This result was supported by the subgroup and sensitivity analyses. In principle, most of the patients in ICU were under severe conditions with lower MAP, likely leading to failure in RRT withdrawal. Besides, competing risk of death appeared to obscure the accurate results of RRT withdrawal. Hence, we might intuitively speculate lower MAP and competing risk of death were associated with failure in RRT withdrawal; however, we were able to disclose the robustness of our results that higher MAP would not be optimal rather than sole target of MAP $\geq 65 \mathrm{mmHg}$. Moreover, we reinforced our results according to evidence that the intervention in hemodynamic stability was not associated with MAP at baseline. On the other hand, some studies investigated patients with more severe conditions with higher mortality (e.g., 60.3\%) [1] and, therefore, the interpretation of our results should be made with caution. Nevertheless, the nature of observational study may not allow for causality and, therefore, future studies are needed to assess whether specific MAP target interventions can improve the outcome of AKI requiring RRT.

Our study has several limitations. First, the retrospective nature of this study may potentially make it susceptible to several forms of bias. For example, a retrospective collection of medical histories from the medical charts might lead to misclassification. Second, we were unable to account for several potential confounders, such as urinary status. However, some patients were initiated RRT soon after admission into our hospital from emergency department. Therefore, we cannot sufficiently ascertain 
Table 4 Multivariate analyses for RRT withdrawal in patients with AKI requiring RRT

\begin{tabular}{|c|c|c|c|c|c|c|c|c|c|}
\hline \multirow[t]{2}{*}{ Covariates } & \multicolumn{3}{|l|}{ Model 1} & \multicolumn{3}{|l|}{ Model 2} & \multicolumn{3}{|l|}{ Model 3} \\
\hline & Adjusted HR & $95 \% \mathrm{CI}$ & $P$ value & Adjusted HR & $95 \% \mathrm{CI}$ & $P$ value & Adjusted HR & $95 \% \mathrm{CI}$ & $P$ value \\
\hline Age & 1.00 & $0.98-1.01$ & 0.364 & 1.00 & $0.99-1.01$ & 0.760 & 1.00 & $0.99-1.01$ & 0.557 \\
\hline Male (vs female) & 0.80 & $0.57-1.13$ & 0.201 & 0.74 & $0.52-1.06$ & 0.098 & 0.73 & $0.51-1.04$ & 0.082 \\
\hline MAP (mmHg) & & & & & & 0.030 & & & 0.010 \\
\hline $\mathrm{MAP}<65$ & & & & 1.01 & $0.59-1.71$ & 0.980 & 1.12 & $0.66-1.92$ & 0.673 \\
\hline $65 \leq \mathrm{MAP}<75$ & & & & 1.00 & Reference & & Reference & Reference & \\
\hline $75 \leq \mathrm{MAP}<85$ & & & & 1.16 & $0.71-1.91$ & 0.549 & 1.19 & $0.72-1.95$ & 0.502 \\
\hline $85 \leq \mathrm{MAP}<95$ & & & & 0.80 & $0.44-1.43$ & 0.443 & 0.73 & $0.40-1.32$ & 0.297 \\
\hline $95 \leq \mathrm{MAP}<105$ & & & & 0.46 & $0.23-0.92$ & 0.028 & 0.42 & $0.21-0.85$ & 0.014 \\
\hline $105 \leq \mathrm{MAP}$ & & & & 0.55 & $0.31-0.98$ & 0.042 & 0.55 & $0.31-0.96$ & 0.036 \\
\hline CVD & & & & 0.83 & $0.58-1.20$ & 0.317 & 0.91 & $0.63-1.33$ & 0.640 \\
\hline CKD & & & & 0.64 & $0.42-0.97$ & 0.037 & 0.63 & $0.41-0.96$ & 0.030 \\
\hline Sepsis & & & & 0.63 & $0.43-0.91$ & 0.015 & 0.69 & $0.47-1.02$ & 0.063 \\
\hline Nephrotoxic agent & & & & 1.07 & $0.74-1.55$ & 0.706 & 1.18 & $0.81-1.71$ & 0.396 \\
\hline Anemia & & & & 0.77 & $0.54-1.08$ & 0.133 & 0.76 & $0.54-1.07$ & 0.113 \\
\hline Hypoalbuminemia & & & & 0.63 & $0.50-0.89$ & 0.008 & 0.70 & $0.49-0.99$ & 0.042 \\
\hline Ventilator & & & & & & & 0.65 & $0.44-0.97$ & 0.035 \\
\hline
\end{tabular}

Model 1 was adjusted for age and sex. Model 2, in addition to model 1, was adjusted for MAP at RRT initiation, the history of CVD and CKD, sepsis, the use of nephrotoxic agents, anemia, and hypoalbuminaemia. Model 3, in addition to model 2, was adjusted for ventilator use

$R R T$ renal replacement therapy, $A K I$ acute kidney injury, $H R$ hazard ratio, $C I$ confidence interval, $M A P$ mean arterial pressure, $C V D$ cardiovascular disease, $C K D$ chronic kidney disease, anemia defined as $\mathrm{Hb}<10.0 \mathrm{~g} / \mathrm{dL}$, hypoalbuminemia defined as Alb $<2.5 \mathrm{~g} / \mathrm{dL}$

Fig. 1 Forest plot demonstrates consistent associations of mean arterial pressure (MAP) at renal replacement therapy (RRT) initiation with RRT withdrawal. Hazard ratio (HR) estimates are adjusted for age, sex, cardiovascular disease (CVD), chronic kidney disease (CKD), sepsis, nephrotoxic agents, anemia, hypoalbuminemia, ventilator use. $C I$ confidence interval, nephrotoxic nephrotoxic agents, $I C U$ intensive care unit

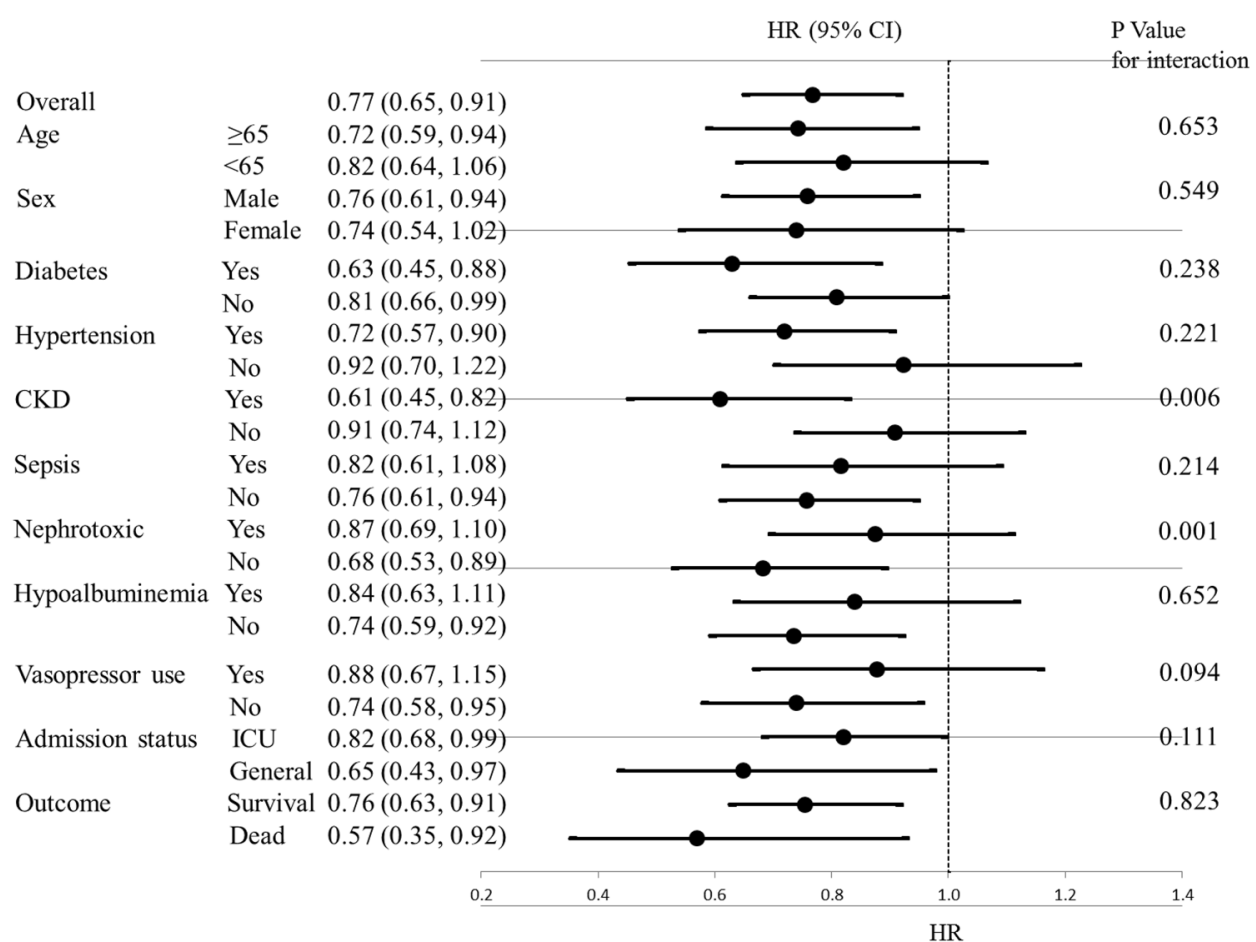

confounders of MAP and RRT withdrawal, external validity of the results may be limited due to the relatively small study population conducted in a single center. Future replication studies in a larger population are warranted to their urine volume and were not able to include urine volume into our analysis. Third, this study was conducted in a single center, which may limit the generalizability of our findings. Although we accounted for the major 
Table 5 Subgroup analysis applied our final model in ICU and general ward patients

\begin{tabular}{|c|c|c|c|c|c|c|}
\hline \multirow[t]{2}{*}{ Covariates } & \multicolumn{3}{|l|}{ ICU } & \multicolumn{3}{|l|}{ General ward } \\
\hline & Adjusted HR & $95 \% \mathrm{CI}$ & $P$ value & Adjusted HR & $95 \% \mathrm{CI}$ & $P$ value \\
\hline Age & 1.00 & $0.98-1.01$ & 0.424 & 1.01 & $0.97-1.04$ & 0.805 \\
\hline Male (vs female) & 0.59 & $0.39-0.87$ & 0.008 & 1.12 & $0.40-3.09$ & 0.833 \\
\hline MAP (mmHg) & & & 0.058 & & & 0.024 \\
\hline $\mathrm{MAP}<65$ & 0.86 & $0.48-1.53$ & 0.614 & 7.21 & $1.16-44.74$ & 0.034 \\
\hline $65 \leq \mathrm{MAP}<75$ & 1.00 & Reference & & 1.00 & Reference & \\
\hline $75 \leq \mathrm{MAP}<85$ & 1.07 & $0.63-1.83$ & 0.796 & 3.43 & $0.62-18.90$ & 0.156 \\
\hline $85 \leq \mathrm{MAP}<95$ & 0.92 & $0.47-1.80$ & 0.804 & 0.83 & $0.15-4.64$ & 0.827 \\
\hline $95 \leq \mathrm{MAP}<105$ & 0.41 & $0.18-0.92$ & 0.030 & 0.93 & $0.16-5.26$ & 0.934 \\
\hline $105 \leq \mathrm{MAP}$ & 0.49 & $0.26-0.92$ & 0.028 & 0.98 & $0.19-5.21$ & 0.983 \\
\hline CVD & 0.81 & $0.52-1.26$ & 0.351 & 0.73 & $0.27-1.95$ & 0.533 \\
\hline CKD & 0.66 & $0.38-1.13$ & 0.131 & 0.42 & $0.18-0.98$ & 0.045 \\
\hline Sepsis & 0.64 & $0.41-0.98$ & 0.040 & 1.39 & $0.48-4.04$ & 0.545 \\
\hline Nephrotoxic agent & 0.92 & $0.61-1.41$ & 0.716 & 1.69 & $0.65-4.39$ & 0.286 \\
\hline Anemia & 0.88 & $0.59-1.32$ & 0.544 & 0.72 & $0.28-1.83$ & 0.489 \\
\hline Hypoalbuminemia & 0.64 & $0.43-0.96$ & 0.032 & 1.09 & $0.44-2.69$ & 0.856 \\
\hline Ventilator & 0.63 & $0.41-0.96$ & 0.033 & 0.18 & $0.03-0.99$ & 0.049 \\
\hline
\end{tabular}

$H R$ hazard ratio, $C I$ confidence interval, $M A P$ mean arterial pressure, $C V D$ cardiovascular disease, $C K D$ chronic kidney disease, anemia defined as $\mathrm{Hb}<10.0 \mathrm{~g} / \mathrm{dL}$, hypoalbuminemia defined as $\mathrm{Alb}<2.5 \mathrm{~g} / \mathrm{dL}$
Table 6 Restricted analyses to survivors applied our final model

\begin{tabular}{llll}
\hline Covariates & \multicolumn{2}{l}{ Survival } & \\
\cline { 2 - 4 } & Adjusted HR & $95 \%$ CI & $P$ value \\
\hline Age & 1.01 & $0.99-1.02$ & 0.167 \\
Male (vs female) & 1.15 & $0.75-1.75$ & 0.523 \\
MAP (mmHg) & & & 0.050 \\
MAP $<65$ & 1.13 & $0.60-2.12$ & 0.706 \\
$65 \leq$ MAP $<75$ & 1.00 & Reference & \\
$75 \leq$ MAP $<85$ & 0.77 & $0.43-1.39$ & 0.391 \\
$85 \leq$ MAP $<95$ & 0.65 & $0.33-1.27$ & 0.208 \\
$95 \leq$ MAP $<105$ & 0.41 & $0.20-0.85$ & 0.016 \\
$105 \leq$ MAP & 0.47 & $0.25-0.88$ & 0.017 \\
CVD & 1.05 & $0.67-1.63$ & 0.845 \\
CKD & 0.46 & $0.27-0.76$ & 0.003 \\
Sepsis & 0.86 & $0.56-1.32$ & 0.493 \\
Nephrotoxic agent & 1.35 & $0.91-1.99$ & 0.134 \\
Anemia & 0.71 & $0.47-1.06$ & 0.093 \\
Hypoalbuminemia & 0.87 & $0.59-1.30$ & 0.497 \\
Ventilator & 0.77 & $0.50-1.19$ & 0.238 \\
\hline
\end{tabular}

$H R$ hazard ratio, $C I$ confidence interval, $M A P$ mean arterial pressure, $C V D$ cardiovascular disease, $C K D$ chronic kidney disease, anemia defined as $\mathrm{Hb}<10.0 \mathrm{~g} / \mathrm{dL}$, hypoalbuminemia defined as Alb $<2.5 \mathrm{~g} /$ $\mathrm{dL}$

explore the generalizability of our findings. Finally, we were only able to assess the short-term kidney outcomes. Although several studies suggest that renal recovery can occur long after hospital discharge (e.g., 90 days-6 months $[40,41])$, the majority of renal recovery would be observed within a short period [42].

In conclusion, CKD, ventilator use, hypoalbuminemia, and MAP were significantly associated with RRT withdrawal among individuals with AKI requiring RRT. Considering that MAP is potentially modifiable through medications, whether interventions of target BP strategy could improve the outcome of AKI requiring RRT may deserve future investigation.

Acknowledgements This study was supported by a Clinical Research Support Grant from the Tokyo Metropolitan 2015-2016.

Author contributions KI designed this study, obtained the fund support, analyzed the data, wrote the manuscript, and submitted the manuscript. JI advised the study design, reviewed the analyses and the manuscript. SI supervised the study. All the authors discussed and reviewed the manuscript.

\section{Compliance with ethical standards}

Conflict of interest The authors declare no competing interests.

Ethical approval We collected the clinical data according to the Guidelines for Epidemiological Studies from The Ministry of Health, Labour and Welfare, Japan. The institutional review board and the Committee of Ethics of Tokyo Metropolitan Bokutoh Hospital approved the study protocol (\# 5 in 2014).

Informed consent The IRB and ethics committee that granted approval waived the need to obtain informed consent for this study. 


\section{References}

1. Uchino S, Kellum JA, Bellomo R, Doig GS, Morimatsu H, Morgera S, et al. Acute renal failure in critically ill patients: a multinational, multicenter study. JAMA. 2005;294:813-18.

2. Kidney Disease: Improving Global Outcome (KDIGO) Acute Kidney Injury Work Group. KDIGO clinical practice guideline for acute kidney injury. Kidney Int Suppl. 2012;2:1-138.

3. Waikar SS, Curhan GC, Wald R, McCarthy EP, Chertow GM. Declining mortality in patients with acute renal failure, 1988 to 2002. J Am Soc Nephrol. 2006;17:1143-50.

4. Kolhe NV, Muirhead AW, Wilkes SR, Fluck RJ, Taal MW. National trends in acute kidney injury requiring dialysis in England between 1998 and 2013. Kidney Int. 2015;88:1161-69.

5. VA/NIH Acute Renal Failure Trial Network. Intensity of renal support in critically ill patients with acute kidney injury. N Engl J Med. 2008;359:7-20.

6. Ng KP, Chanouzas D, Fallouh B, Baharani J. Short and longterm outcome of patients with severe acute kidney injury requiring renal replacement therapy. QJM. 2012;105:33-9.

7. Hsu CY, Vittinghoff E, Lin F, Shlipak MG. The incidence of end-stage renal disease is increasing faster than the prevalence of chronic renal insufficiency. Ann Intern Med. 2004;141:95-101.

8. Wald R, Quinn RR, Luo J, Li P, Scales DC, Mamdani MM, et al. Chronic dialysis and death among survivors of acute kidney injury requiring dialysis. JAMA. 2009;302:1179-85.

9. Wu VC, Ko WJ, Chang HW, Chen YW, Lin YF, Shiao CC, et al. Risk factors of early redialysis after weaning from postoperative acute renal replacement therapy. Intensive Care Med. 2008;34:101-8.

10. Yang T, Sun S, Zhao Y, Liu Q, Han M, Lin L, et al. Biomarkers upon discontinuation of renal replacement therapy predict 60-day survival and renal recovery in critically ill patients with acute kidney injury. Hemodial Int Symp Home Hemodial. 2018;22:56-65.

11. Uchino S, Bellomo R, Morimatsu H, Morgera S, Schetz M, Tan I, et al. Discontinuation of continuous renal replacement therapy: a post hoc analysis of a prospective multicenter observational study. Crit Care med. 2009;37:2576-82.

12. Chao CT, Wu VC, Lai CF, Shiao CC, Huang TM, Wu PC, et al. Advanced age affects the outcome-predictive power of RIFLE classification in geriatric patients with acute kidney injury. Kidney Int. 2012;82:920-7.

13. Gaião SM, Gomes AA, Paiva JA. Prognostics factors for mortality and renal recovery in critically ill patients with acute kidney injury and renal replacement therapy. Rev Bras Ter Intensiva. 2016;28:70-7.

14. Ostermann M, Chang RW. Correlation between parameters at initiation of renal replacement therapy and outcome in patients with acute kidney injury. Crit Care. 2009;13:R175.

15. Yuasa S, Takahashi N, Shoji T, Uchida K, Kiyomoto H, Hashimoto $\mathrm{M}$, et al. A simple and early prognostic index for acute renal failure patients requiring renal replacement therapy. Artif Organs. 1998;22:273-8.

16. Yasuda H, Kato A, Fujigaki Y, Hishida A. Incidence and clinical outcomes of acute kidney injury requiring renal replacement therapy in Japan. Ther Apher Dial. 2010;14:541-6.

17. Ulusoy S, Arı D, Ozkan G, Cansız M, Kaynar K. The frequency and outcome of acute kidney injury in a tertiary hospital: which factors affect mortality? Artif Organs. 2015;39:597-606.

18. Rocha E, Soares M, Valente C, Nogueira L, Bonomo H Jr, Godinho $\mathrm{M}$, et al. Outcomes of critically ill patients with acute kidney injury and end-stage renal disease requiring renal replacement therapy: a case-control study. Nephrol Dial Transplant. 2009;24:1925-30.
19. Oh HJ, Shin DH, Lee MJ, Ko KI, Kim CH, Koo HM, et al. Urine output is associated with prognosis in patients with acute kidney injury requiring continuous renal replacement therapy. J Crit Care. 2013;28:379-88.

20. Prescott GJ, Metcalfe W, Baharani J, Khan IH, Simpson K, Smith WC, et al. A prospective national study of acute renal failure treated with RRT: incidence, aetiology and outcomes. Nephrol Dial Transplant. 2007;22:2513-19.

21. Schiffl H. Renal recovery from acute tubular necrosis requiring renal replacement therapy: a prospective study in critically ill patients. Nephrol Dial Transplant. 2006;21:1248-52.

22. Bagshaw SM, Uchino S, Bellomo R, Morimatsu H, Morgera S, Schetz M, et al. Septic acute kidney injury in critically ill patients: clinical characteristics and outcomes. Clin J Am Soc Nephrol. 2007;2:431-9.

23. Alobaidi R, Basu RK, Goldstein SL, Bagshaw SM. Sepsis-associated acute kidney injury. Semin Nephrol. 2015;35:2-11.

24. Levy MM, Fink MP, Marshall JC, Abraham E, Angus D, Cook D, et al. 2001 SCCM/ESICM/ACCP/ATS/SIS international sepsis definitions conference. Crit Care Med. 2003;31:1250-56.

25. Uchino S, Doig GS, Bellomo R, Morimatsu H, Morgera S, Schetz $\mathrm{M}$, et al. Diuretics and mortality in acute renal failure. Crit Care Med. 2004;32:1669-77.

26. Mehta RL, Pascual MT, Soroko S, Chertow GM. Diuretics, mortality, and nonrecovery of renal function in acute renal failure. JAMA. 2002;288:2547-53.

27. Heung M, Wolfgram DF, Kommareddi M, Hu Y, Song PX, Ojo AO. Fluid overload at initiation of renal replacement therapy is associated with lack of renal recovery in patients with acute kidney injury. Nephrol Dial Transplant. 2012;27:956-61.

28. Kidney Disease: Improving Global Outcomes (KDIGO) Anemia Work Group. KDIGO clinical practice guideline for anemia in chronic kidney disease. Kidney Int Suppl. 2012;2:279-335.

29. Thongprayoon C, Cheungpasitporn W, Mao MA, Sakhuja A, Kashani K. U-shape association of serum albumin level and acute kidney injury risk in hospitalized patients. PLoS One. 2018;Jun 21;13(6):e0199153.

30. Yu MY, Lee SW, Baek SH, Na KY, Chae DW, Chin HJ, Kim S. Hypoalbuminemia at admission predicts the development of acute kidney injury in hospitalized patients: a retrospective cohort study. PLoS One. 2017;12(7):e0180750.

31. Corrêa TD, Vuda M, Takala J, Djafarzadeh S, Silva E, Jakob SM. Increasing mean arterial blood pressure in sepsis: effects on fluid balance, vasopressor load and renal function. Crit Care. 2013;17:R21.

32. Wonnacott A, Meran S, Amphlett B, Talabani B, Phillips A. Epidemiology and outcomes in community-acquired versus hospitalacquired AKI. Clin J Am Soc Nephrol. 2014;Jun 6;9(6):1007-14.

33. Holmes J, Geen J, Phillips B, Williams JD, Phillips AO, Welsh AKI, Steering Group. Community acquired acute kidney injury: findings from a large population cohort. QJM. 2017 Nov;1(11):741-6. 110(.

34. Metcalfe W, Simpson M, Khan IH, Prescott GJ, Simpson K, Smith WC, et al. Acute renal failure requiring renal replacement therapy: incidence and outcome. QJM. 2002;95:579-83.

35. Uehlinger DE, Jakob SM, Ferrari P, Eichelberger M, Huynh-Do $\mathrm{U}$, Marti HP, et al. Comparison of continuous and intermittent renal replacement therapy for acute renal failure. Nephrol Dial Transplant. 2005;20:1630-37.

36. Ishani A, Xue JL, Himmelfarb J, Eggers PW, Kimmel PL, Molitoris BA, et al. Acute kidney injury increases risk of ESRD among elderly. J Am Soc Nephrol. 2009;20:223-8.

37. Griffin KA. Hypertensive kidney injury and the progression of chronic kidney disease. Hypertension. 2017;70:687-94.

38. Wu X, Jiang Z, Ying J, Han Y, Chen Z. Optimal blood pressure decreases acute kidney injury after gastrointestinal surgery 
in elderly hypertensive patients: a randomized study: optimal blood pressure reduces acute kidney injury. J Clin Anesth. 2017;43:77-83.

39. Skarupskienė I, Adukauskienė D, Kuzminskienė J, Rimkutė L, Balčiuvienė V, Žiginskienė E, et al. Mortality prediction in patients with acute kidney injury requiring renal replacement therapy after cardiac surgery. Medicina (Kaunas). 2017;53:217-23.

40. Bagshaw SM, Laupland KB, Doig CJ, Mortis G, Fick GH, Mucenski M, et al. Prognosis for long-term survival and renal recovery in critically ill patients with severe acute renal failure: a populationbased study. Crit Care. 2005;9:R700-9.

41. Liaño F, Felipe C, Tenorio MT, Rivera M, Abraira V, Sáez-deUrturi JM, et al. Long-term outcome of acute tubular necrosis: a contribution to its natural history. Kidney Int. 2007;71:679-86.
42. Bagshaw SM, Mortis G, Godinez-Luna T, Doig CJ, Laupland KB. Renal recovery after severe acute renal failure. Int J Artif Organs. 2006;29:1023-30.

Publisher's Note Springer Nature remains neutral with regard to jurisdictional claims in published maps and institutional affiliations. 